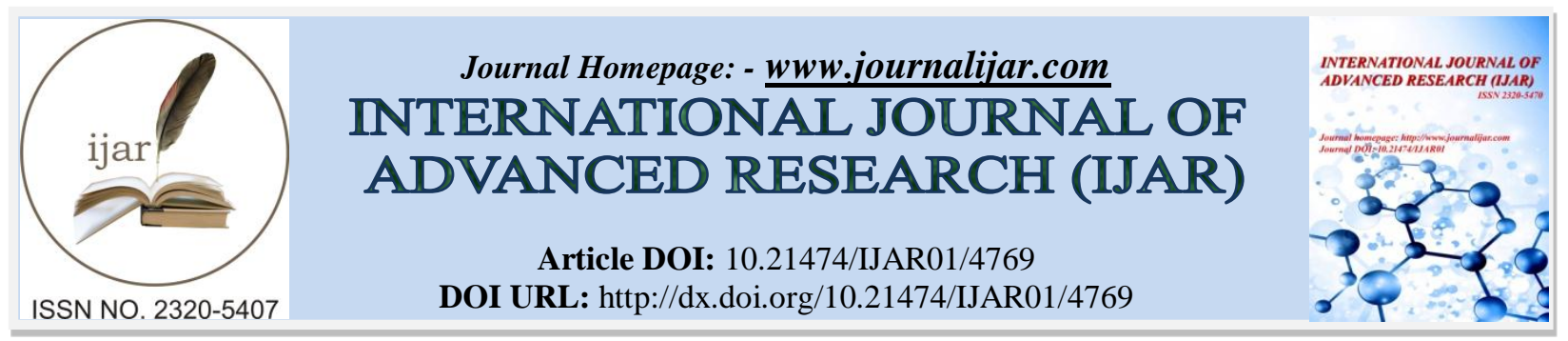

RESEARCH ARTICLE

\title{
STUDY OF DRUG PRESCRIBING AND USE PATTERN IN PAEDIATRIC BRONCHIAL ASTHMA PATIENTS.
}

\section{Minju Saji, Lida Elizabeth Raju, Sagy P Thomas, P. K. Manna., S. Ramesh and Saravanan. S.}

1. Department of Pharmacy Practice, Rajah Muthiah Medical College and Hospital (RMMCH), Chidambaram608001, India.

2. Department of Pharmacy, Annamalai University, Chidambaram-608001, India.

\section{Manuscript Info}

Manuscript History

Received: 7 May 2017

Final Accepted: 9 June 2017

Published: July 2017

Key words:-

$\beta$-agonists, Bronchial asthma, Medication adherence, Quality of life.

\section{Abstract}

Background: Asthma is a condition in which a persons airways become inflamed,narrow and swell and produce extra mucus, which makes it difficult to breathe.

Aim and Objective: This study aims on describing the drug prescribing pattern,medication adherence,quality of life,handling of inhalers,lung function test and cost of illness in 110 paediatric bronchial asthma patients in a tertiary care hospital for duration of six months.

Results: Overall 110 patients were enrolled in the study and its found that male patients $(60.90 \%)$ are more prone to asthmatic attacks than female patients $(39.10 \%)$. $\beta$-agonists (Salbutamol,) was the most commonly used bronchodialator followed by corticosteroids $(82.72 \%)$, antibiotics $(56.36 \%)$, anti-histamines(30\%)anti inflammatory(29.9\%), antitussives $(23.63 \%)$ and methylxanthines(11.81\%). Drugs used in RMMCH were compared to various EDL (Essential drug list) which complied with national EDL.The FVC and FEV were assessed among the patients during their admission and discharge time.The statistical analysis of the data of the two groups (baseline and discharge) for $\mathrm{FVC}(\mathrm{P}=<0.001)$ and $\operatorname{FEV}(\mathrm{p}=<0.008)$ shows its significance. $20.9 \% .61 .81 \% .80 .9 \%$ of the patients has shown correct usage of inhalers during baseline,after first and second counseling.A significant improvement in quality of life was assessed during pre and post counseling using Mann-Whitney rank sum test.The score of $\operatorname{low}(55.45 \%)$ medium $(32.72 \%)$ and high $(11.81 \%)$ medication adherence patients was found on pre-counseling and on post-counseling low(17.27\%),medium(55.45\%) and high(28.18\%) medication adherence was observed.Hospitalization charges are accounting for $39.3 \%$ and medical charges are accounting for $24.21 \%$ on an average of 6 days of admission in the hospital.

Conclusion: Patient counseling aided and had a positive impact on patients understanding of their illness and the role of medications in its treatment,improved medication adherence and improved quality of life for the patients. 


\section{Introduction:-}

Asthma is a chronic inflammatory disorder of airways. It is a disease of increasing prevalence that is a result of genetic predisposition and environmental interactions and one of the most common chronic diseases of childhood. It is characterized by recurrent attacks of breathlessness and wheezing, that may vary in severity and frequency from person to person. ${ }^{1}$ In an attack the lining of the passage swell causing the airways to narrow and reducing the flow of the air in and out of the lungs.Evidence suggests that prevalence of asthma worldwide is around 200 million with a mortality of around 0.2 million per year and is estimated to account for one in every 250 deaths worldwide ${ }^{2}$

Three to five percent of paediatric population in India is affected by asthma where as in adults it ranges from 3-11\%. In this study, an attempt has been made to study general prescribing pattern,cost analysis, counseling patient on disease condition, medication use, and medication Adherence and improving the quality of life. ${ }^{5}$ Patient counseling had a positive impact on patients understanding of their illness and the role of medications in its treatment,improved medication adherence, and improved quality of life for the patient.Moreover a good professional rapport has been built between the pharmacist and the patient. Bronchial asthma is a chronic disease which requires ongoing therapeutic monitoring. The acute exacerbations of asthma leading to morbidity, increased cost and death often preventable.,

Adherence is a primary determiner of the effectiveness of treatment because poor adherence attenuates optimum clinical benefit. Good adherence improves the effectiveness of interventions aimed at promoting healthy lifestyles, such as diet modification, increased physical activity, and of the pharmacological-based risk-reduction interventions. It also affects secondary prevention and disease treatment interventions. ${ }^{8}$ This study aims at current prescribing pattern of asthmatic medications in patients below 14 years and the role of pharmacists in improving patient's health.

\section{Methodology:-}

The study was a non-invasive cross sectional prospective observational study carried out over 6 month period incorporating both descriptive and inferential analyses. The study was approved by the Institutional Human Ethics Committee \& Informed Consent Form was obtained from the eligible patients. Patients were selected on the basis of inclusion criteria and exclusion criteria.

Patients of age group below 14 years who were prescribed with at least one anti- asthmatic drug, Patients who were diagnosed with bronchial asthma and under prescription are included in this study. Patients who were not willing to cooperate, Patients who were having other respiratory problems, cardiac problems are excluded from this study.

The patients were further classified into 3 age groups 0-4, 5-9, and 10-14years . Convenient sampling was used to recruit all eligible patients and a validated data collection form was used to collect data from the patients. The data collection form provides the information regarding the demographic details of the patient which includes age, sex, past history, family history, medication history and treatment giving to the patient. Participants were inquired about their understanding while completing the form. Their feedbacks were then used to improvise data collection for their easy understanding. In the present study the prescribing pattern was studied to evaluate the drug- prescribing trend of antiasthmatics drugs by physicians in RMMCH (Rajah Muthiah Medical College and Hospital). In this study the categories of drugs, antibiotic prescribing pattern, drug therapy regimens, list of drugs complying with WHO (World Health Organisation), NATIONAL, T.N (Tamil Nadu) essential drug list was analysed by including the number of prescriptions. Finally 110 prescriptions were screened and results were tabulated according to their percentages and number of prescriptions.

The quality of life was measured by using the paediatric asthma care givers Quality of life (QoL) questionnaire. Medication adherence was adopted by using Morisky adherence scale and the results are interpreted based on the level of adherence as low, medium and high. ${ }^{9}$ In this present study analysis was carried out by comparing the pre and post counseling results of the parameters under concern. All the 110 patients are divided in to two groups and intake was performed in equal proportion with similar age groups and disease condition. The patients knowledge and attitude towards their disease and their quality of life improvement was compared at the admission period and the discharge period and thus the effectiveness of counseling was assessed. A statistical test was performed using student't' test using the statistical package for social sciences version 16 (SPSS Inc, Chicago, IL, USA) for the analysis of data at a significance level of $\mathrm{P}=<0.001$. This level of significance is obtained at 60 degrees of freedom, $95 \%$ confidence interval. 


\section{Patient Characteristics:-}

A total of 110 patients were enrolled in the study. Out of which $67(60.90 \%)$ are males and 43(39.10\%) are females. Majority of the patients were in the age group of 5-9 years (47.27\%) followed by 0-4 years (40\%) and 10-14(12.73\%). Climate is the primary cause of bronchial asthma accounts for $61.81 \%$ followed by dust, pollen and drugs. Represented in (Figure 1).

Figure 1:- causes of asthma:

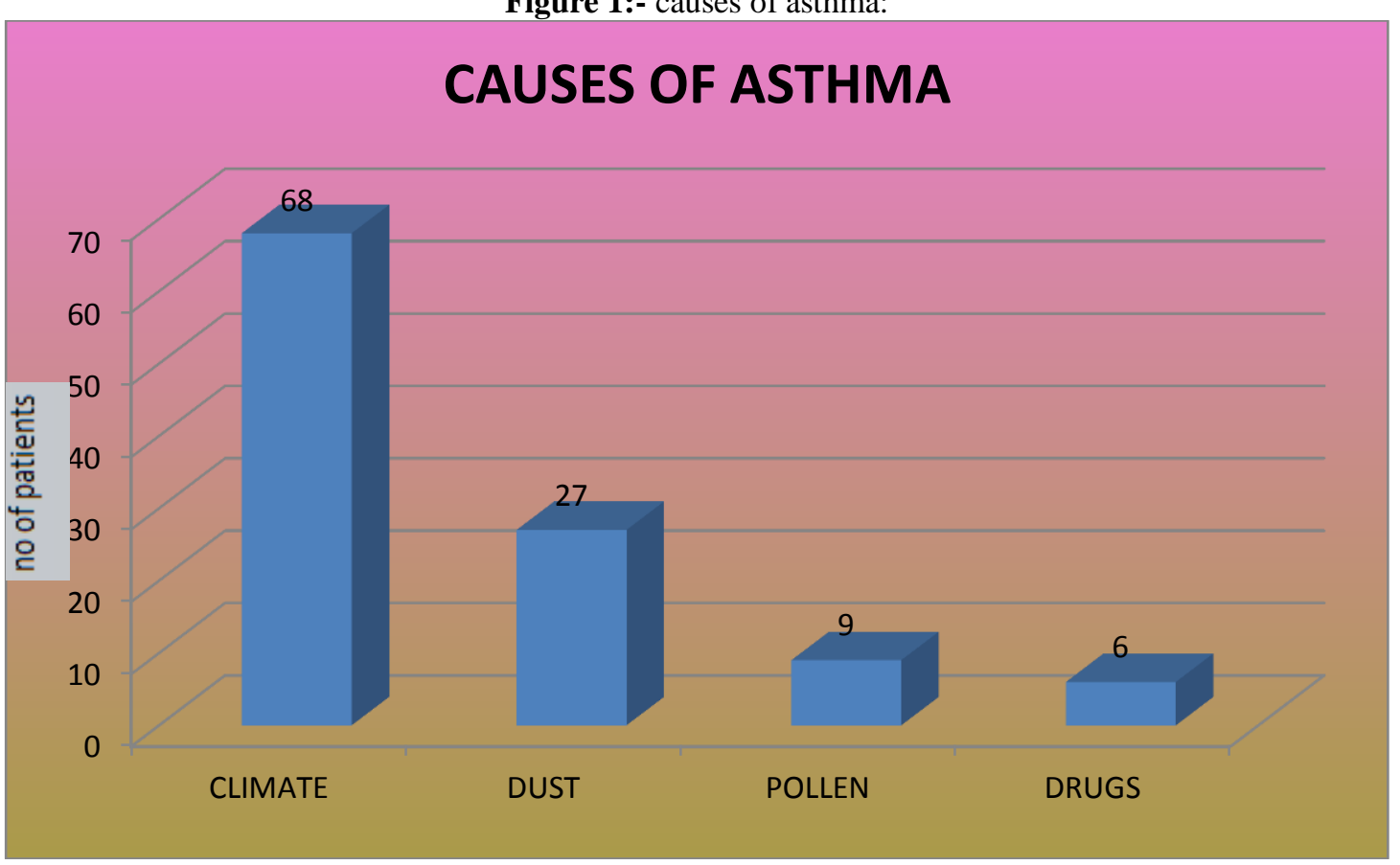

\section{Prescribing pattern:-}

$\beta$-agonists (Salbutamol, Ipratropium bromide) accounts for highest number of prescriptions i.e, 98 prescriptions followed by Corticosteroids (Hydrocortisone, Predniso-lone, beclomethasone) and antibiotics(Crystalline penicillin, Amikacin, Amoxicillin),Antihistamines(Epinephrine,montelukast),anti-inflammatory(budesonide), andAntitussives(Mucolytics, Cough suppressants) 91, 62, 33, 32 and 26 prescriptions respectively (shown in Table 1). Whereas Methylxanthines( Theophylline) are the least prescribed category drugs. Crystalline penicillin was present in highest number of prescriptions (53.22\%) followed by Amikacin (45.16\%), Gentamycin (29.03\%), Cefotaxime (27.41\%), Amoxicillin(25.80\%), Ampicillin(17.74\%) and Doxycycline(6.45\%). Multiple drug therapy was the most common type of drug therapy regimen prescribed in most of the prescriptions. In this study drugs used in RMMCH were compared to various EDL (Essential drug list) and it was found that $100 \%$ of drugs are complied with national EDL (shown in Table 2). List of all anti-asthmatic drugs mentioned in WHO EDL, National EDL, TN EDL and drugs used in RMMCH are tabulated in (Table 3).

Table 1:- Prescribing Pattern in RMMCH

\begin{tabular}{|l|l|l|l|}
\hline CATEGORY & NAME OF DRUGS & $\begin{array}{l}\text { No. } \\
\text { PRESCRIPTION }\end{array}$ & OF \\
\hline CORTICOSTEROIDS & $\begin{array}{l}\text { Hydrocortisone, Prednisolone, } \\
\text { Beclomethasone }\end{array}$ & 91 & $82.72 \%$ \\
& $\begin{array}{l}\text { Salbutamol, Ipratropium } \\
\text { bromide }\end{array}$ & 98 & $89.09 \%$ \\
\hline METHYLXANTHINE & Theophylline & 13 & $11.81 \%$ \\
\hline ANTIHISTAMINES & Epinephrine,montelukast & 33 & $30 \%$ \\
\hline ANTIBIOTICS & Crystalline penicillin, & 62 & $56.36 \%$ \\
\hline
\end{tabular}




\begin{tabular}{|l|l|l|l|}
\hline & Amikacin, Amoxicillin. & & \\
\hline ANTITUSSIVES Cough & $\begin{array}{l}\text { Mucolytics, } \\
\text { suppressants }\end{array}$ & $23.63 \%$ \\
\hline ANTI-INFLAMMATORY & Budesonide & 32 & $29.09 \%$ \\
\hline
\end{tabular}

Table 2:- Percentage Of Anti- Asthmatic Belonging To Essential Drug Lists (Who, National, Tn)

Below tabular column shows the number and percentage of anti-asthmatics prescribed from the WHO, NATIONAL and TAMILNADU essential drug lists, total number of drugs in WHO, NATIONAL and T.N EDL

\begin{tabular}{|c|c|c|c|c|c|c|c|c|c|c|}
\hline \multirow[t]{2}{*}{$\begin{array}{l}\text { SL } \\
\text { No. }\end{array}$} & $\begin{array}{l}\text { TOTAL } \\
\text { DRUGS }\end{array}$ & No. OF & \multicolumn{2}{|c|}{ ANTI-ASTHMATIC } & \multicolumn{3}{|c|}{$\begin{array}{lr}\text { ACCORDING } & \text { TO } \\
\text { PRESCRIBTION } & \text { No. } \\
\text { OF } & \text { DRUG } \\
\text { BELONGING TO } & \end{array}$} & \multicolumn{2}{|c|}{$\begin{array}{l}\% \quad \text { OF } \\
\text { BELONGING TO }\end{array}$} & DRUG \\
\hline & $\begin{array}{l}\text { IN } \\
\text { WHO } \\
\text { EDL }\end{array}$ & $\begin{array}{l}\text { IN } \\
\text { NATIONAL } \\
\text { EDL }\end{array}$ & $\begin{array}{l}\text { IN } \\
\text { TN } \\
\text { EDL }\end{array}$ & $\begin{array}{l}\text { IN } \\
\text { RMMCH }\end{array}$ & $\begin{array}{l}\text { WHO } \\
\text { EDL }\end{array}$ & $\begin{array}{l}\mathbf{N} \\
\text { EDL }\end{array}$ & $\begin{array}{l}\text { TN } \\
\text { EDL }\end{array}$ & $\begin{array}{l}\text { WHO } \\
\text { EDL }\end{array}$ & N EDL & TN EDL \\
\hline 1 & 5 & 4 & 5 & 5 & 5 & 4 & 3 & $100 \%$ & $100 \%$ & $60 \%$ \\
\hline
\end{tabular}

Table 3:-List of anti-asthmatic drugs in rmmch, who edl, national edl \& tn edl.

\begin{tabular}{|c|c|c|c|c|}
\hline S.no & $\begin{array}{l}\text { DRUGS LIST IN WHO- } \\
\text { EDL }\end{array}$ & $\begin{array}{lrr}\text { DRUGS } & \text { LIST } & \text { IN } \\
\text { NATIONAL } & \text { EDL } & \end{array}$ & $\begin{array}{lll}\text { DRUGS } & \text { LIST } & \text { IN } \\
\text { TN-EDL } & & \end{array}$ & $\begin{array}{l}\text { DRUGS LIST IN } \\
\text { RMMCH }\end{array}$ \\
\hline 1. & $\begin{array}{l}\text { BECLOMETASONE } \\
\text { Inhalation } \\
\text { (aerosol):100mcg per } \\
\text { dose. }\end{array}$ & $\begin{array}{l}\text { IPRATROPIUM } \\
\text { BROMIDE Inhalation } \\
\text { 20mcg/metered dose }\end{array}$ & $\begin{array}{l}\text { THEOPHYLLINE \& } \\
\text { ETOFHYLLINE } \\
\text { Anhydrous } \\
\text { theophylline } 50.6 \mathrm{mg} \\
\text { Etofyline } 169.4 \mathrm{mg}\end{array}$ & THEOPHYLLINE \\
\hline 2. & $\begin{array}{l}\text { BUDESONIDE } \\
\text { Inhalation } \\
\text { (aerosol): } 100 \mathrm{mcg} \text {; } \\
\text { 200mcg per dose. }\end{array}$ & $\begin{array}{l}\text { SALBUTAMOL } \\
\text { Tab } 2 \mathrm{mg}, 4 \mathrm{mg} \\
\text { Syrup } 2 \mathrm{mg} / 5 \mathrm{ml} \\
\text { Inhalation } 100 \mathrm{mcg} / \text { dose }\end{array}$ & $\begin{array}{l}\text { THEOPHYLLINE } \\
\text { IP } 23 \mathrm{mg}\end{array}$ & SALBUTAMOL \\
\hline 3. & $\begin{array}{l}\text { EPINEPHRINE } \\
\text { Inj. } 1 \mathrm{mg} \text { in } 1-\mathrm{ml} \text { ampoule }\end{array}$ & $\begin{array}{l}\text { BECLOMETHASONE } \\
\text { DIPROPIONATE } \\
\text { Inhalation: } 50 \mathrm{mcg} \text {, } \\
\text { 250mcg/dose. }\end{array}$ & $\begin{array}{l}\text { ETOPHYLLINE } \\
\text { IP } 77 \mathrm{mg}\end{array}$ & $\begin{array}{l}\text { IPRATROPIUM } \\
\text { BROMIDE }\end{array}$ \\
\hline 4. & $\begin{array}{l}\text { IPRATROPIUM } \\
\text { BROMIDE Inhalation } \\
\text { (aerosol): } 20 \mathrm{mcg}\end{array}$ & $\begin{array}{l}\text { HYDROCORTISONE } \\
\text { SODIUM SUCCINATE } \\
\text { Injection : } \quad 100 \mathrm{mcg} \text {, } \\
\text { 200mcg, 400mcg }\end{array}$ & $\begin{array}{l}\text { SALBUTAMOL } \\
\text { Nebulizer- } 5 \mathrm{mg} / \mathrm{ml}\end{array}$ & BUDESONIDE \\
\hline 5. & $\begin{array}{l}\text { SALBUTAMOL } \\
\text { Neb: 5mg; } \\
\text { Inj: 50mg. } \\
\text { Inhalation } \\
\text { (aerosol):100mg }\end{array}$ & & $\begin{array}{l}\text { SALBUTAMOL } \\
\text { SULPHATE } \\
\text { Tab I.P 4mg }\end{array}$ & \\
\hline
\end{tabular}

Table 4:- Antibiotics prescribed:

Antibiotics are the most common irrationally prescribed and used drugs. The following are the common antibiotics used in the treatment of bronchial asthma. Below tabular column represents the number and percentage of prescriptions with antibiotics.

\begin{tabular}{|l|l|l|}
\hline NAME OF DRUG & NO. OF PRESCRIPTIONS & \% OF PRESCRIPTIONS \\
\hline CRYSTILLINE PENCILLIN & 33 & $53.22 \%$ \\
\hline AMIKACIN & 28 & $45.16 \%$ \\
\hline AMOXICILLIN & 16 & $25.80 \%$ \\
\hline
\end{tabular}




\begin{tabular}{|l|l|ll|}
\hline AMPICILLIN & 11 & $17.74 \%$ & \\
\hline GENTAMYCIN & 18 & $29.03 \%$ & \\
\hline DOXYCYCLINE & 4 & \multicolumn{2}{|c|}{$6.45 \%$} \\
\hline CEFOTAXIME & 17 & $27.41 \%$ & \\
\hline
\end{tabular}

Lung function test:-

FEV (Forced Expiratory Volume) and FVC (Forced Vital Capacity) tests were assessed among the patients during their baseline and discharge time (as shown in Table 5) and their statistical significance differences were measured.

Table 5:- Assessment of Lung Function Tests

Pre- and Post- Intervention values of forced vital capacity (FVC) and forced expiratory volume (FEV).

\begin{tabular}{|l|l|l|l|}
\hline & BASELINE & DURING DISCHARGE & $\begin{array}{l}\text { DIFFERENCE } \\
\text { (P VALUE) }\end{array}$ \\
\hline $\begin{array}{l}\text { FVC (FORCED VITAL } \\
\text { CAPACITY)* }\end{array}$ & $3.08 \pm 0.27$ & $3.39 \pm 0.32$ & $<0.001$ \\
\hline $\begin{array}{l}\text { FEV(FORCED } \\
\text { EXPIRATORY VOLUME)* }\end{array}$ & $2.41 \pm 0.76$ & $2.97 \pm 0.82$ & $<0.008$ \\
\hline
\end{tabular}

*values are mean \pm SD for $n=110$

FVC:

* The difference in the mean values of the two groups (baseline and discharge) is greater than would be expected byChance; there is a statistically significant difference between the baseline and discharge groups $(\mathrm{P}=<0.001) . \mathrm{t}=$ 2.803 .

$\mathrm{FEV}_{1}$ :

* The difference in the mean values of the two groups $\{$ baseline and discharge $\}$ is greater than would be expected byChance; there is a statistically significant difference between the baseline and discharge groups $(\mathrm{P}=<0.008) . \mathrm{t}=$ 2.743 .

Inhaler handling assessment:-

Inhaler handling assessment was done during baseline, after first counseling and after second counseling and thus the improvement was assessed as shown in (Table 6).

Table 6:- Inhaler handling assessment:

\begin{tabular}{|l|l|l|c|}
\hline USERS & Baseline & After first counseling & After second counseling \\
\hline $\begin{array}{l}\text { Number of incorrect } \\
\text { users }\end{array}$ & $87(79.09 \%)$ & $42(38.18 \%)$ & $21(19.09 \%)$ \\
\hline Number of correct users & $23(20.9 \%)$ & $68(61.81 \%)$ & $89(80.9 \%)$ \\
\hline
\end{tabular}

Quality of life assessment:-

By using the paediatric asthma care givers quality of life questionnaire mean values are noted during pre counseling and post counseling. These mean values are noted in (Table 7)

Table 7: Assessment of quality of life:

The results of quality of life assessment done by using the paediatric asthma caregiver's quality of life questionnaire are furnished in table 13. The results indicates significant improvement in quality of life after intervention by student clinical pharmacist.

\begin{tabular}{|l|l|l|l|}
\hline & $\begin{array}{l}\text { PRE } \\
\text { COUNSELING }\end{array}$ & POST COUNSELING & SIGNIFICANCE \\
\hline Physical activity domain & $43.21 \pm 5.83$ & $56.21 \pm 7.86$ & YES \\
\hline Emotional domain & $44.73 \pm 5.84$ & $48.59 \pm 6.36$ & YES \\
\hline
\end{tabular}

STATISTICAL ANALYSIS OF DATA USING Mann-Whitney Rank Sum Test

Physical activity domain:

The difference in the mean values of physical activity domain for pre-counseling and post-counseling group is greater than would be expected by Chance; there is a statistically significant difference between the input groups ( $\mathrm{P}$ $=<0.001) \cdot t=7.396$ 
Emotional activity domain

The difference in the mean values of emotional activity domain for pre-counseling and post-counseling group is greater than would be expected by Chance; there is a statistically significant difference between the input groups $\mathrm{t}=$ $1.844(\mathrm{P}=0.070)$

\section{Medication adherence}

Medication adherence results are noted during pre-counseling and post counseling.

The following tabular column represents the differences in mean values of forced vital capacity and forced expiratory volume 1 in test and control groups before and after the intervention.

Table 8:- Medication adherence analysis::

Medication adherence results were tabulated below by using morisky's medication adherence scale. Results were tabulated as low, medium, and high.

Medication Adherence In Enrolled Patients (N=110)

\begin{tabular}{|l|c|c|c|c|c|c|}
\hline \multirow{2}{*}{ Number of patients } & \multicolumn{3}{|c|}{ Pre-counseling } & \multicolumn{2}{l|}{ Post-counseling } \\
\cline { 2 - 7 } & $\begin{array}{l}\text { Low } \\
\text { (greater } \\
\text { than 2) }\end{array}$ & $\begin{array}{l}\text { Medium } \\
\text { (1or 2) }\end{array}$ & High(=0) & $\begin{array}{l}\text { Low(greater } \\
\text { than2) }\end{array}$ & $\begin{array}{l}\text { Medium(1 } \\
\text { or2) }\end{array}$ & High(=0) \\
\cline { 2 - 8 } & 61 & 36 & 13 & 19 & 61 & 30 \\
\hline Percentage(\%) & $55.45 \%$ & $32.72 \%$ & $11.81 \%$ & $17.27 \%$ & $55.45 \%$ & $28.18 \%$ \\
\hline
\end{tabular}

Table 9:- Cost of illness:

On an average of 6 days of hospitalization, the cost burden per patient / per day is Rs.339. On overall direct medical charges are high when compared to direct non-medical charges. It accounts of RS 2032 on 6 days hospitalization.

\begin{tabular}{|l|l|l|l|}
\hline TYPE OF CHARGES & $\begin{array}{l}\text { PER } \\
\text { PERDAY }\end{array}$ & PATIENT/ & TOTAL COST \\
\hline \multicolumn{1}{|c|}{ DIRECT MEDICAL CHARGES } \\
\hline BED CHARGES & 100 & 600 & $29.5 \%$ \\
\hline ADMISSION CHARGES & 33.3 & 200 & $9.8 \%$ \\
\hline MEDICAL CHARGES & 82 & 492 & $24.21 \%$ \\
\hline DIRECT- NON MEDICAL CHARGES & 200 & $9.8 \%$ \\
\hline LAB DATA & 33.3 & 300 & $14.76 \%$ \\
\hline TRAVEL EXPENSES & 50 & 240 & $11.81 \%$ \\
\hline MISCELLANEOUS & 40 & 2032 & $100 \%$ \\
\hline \multicolumn{1}{|l|}{ INDIRECT COST- NOT MEASURED } \\
\hline TOTAL & 339 & \\
\hline
\end{tabular}

\section{Conclusion:-}

Our study showed that male is more affected with asthma than female. Patients of age group 5-09 more affected than any other age groups. B-agonists and corticosteroids are the most commonly prescribed drugs for asthma followed by antibiotics and antihistamines. Most of the treatment strategies are adopted from WHO guidelines and WHO EDL. Patient education increased the knowledge about Asthma and importance of self-care, and lifestyle modifications that can lead to better control of the disease among the patients. By the end of our study there was a significant increase in the medication adherence score. It is evident that Patient education produced a significant improvement in quality of life, medication knowledge and the effect in adherence behaviour. By the end of our study there was a significant increase in the mean score of QoL for the patients. At base line all patients had poor knowledge and attitude towards their disease and thus poor QoL.Medications and hospitalization charges account for the most part of direct cost can be overcome due to patient's education.Medication adherence results suggest that more involvement of pharmacist in patient care yields better therapeutic outcomes. Pharmacist holds an important role in educating the patient about disease there by avoiding the trigger factors and reducing the hospitalizations. In conclusion, patient counseling aided and had a positive impact on patient's understanding of their illness and the role of medications in its treatment, improved medication adherence, and 
improved Quality of life for the patients. Moreover, a good professional rapport has been built between the Pharmacist and the Patient.

\section{Conflict Of Interest:-}

The author has no conflict of interest

\section{Acknowledgements:-}

We express our profound \& sincere gratitude to Dr.S.Ramesh, Professor\&Head,Department of paediatrics, Dr. P.K. Manna, Professor\&Head, Department Of Pharmacy, and Dr Saravanan S MD , Reader, Department Of Pediatrics, RMMCH Annamalai University, Anna-malai Nagar, for their valuable guidance and support, constant inspiration, kind co-operation and great intend to us to fulfill our work in a successful manner

\section{Highlights of Paper}

Made a clear attempt to show the general prescribing pattern of physicians in bronchial asthmatic paediatric patients.

Impact of patient counseling was evaluated and shown how significant the impact was.

Pharmaceutical care is provided and emphasized its importance in pediatric patients.

\section{Authors Profile}

Minju Saji, Lida Elizabeth Raju, Sagy P Thomas: Completed 5 years Pharm d. And presently working as intern in super speciality hospital rajah muthiah medical college and hospital annamalai university, tamil nadu.. We are intrested in the fields of clinical research, clinical pharmacy, pharmacovigilance, public health sciences. Having an experience in designing patient's therapeutic plan and providing pharmaceutical care, participating in daily ward rounds, patient counseling, assessment of drug related problems, measurement of therapeutic outcomes and drug information services in wards like obstetrics and gynaecology, paediatrics, surgery and general medicine..

\section{References:-}

1. Joseph Dipiro T, Robert Talbert L, Gary Yee C, et al. pharmacotherapy A Pathophysiologic Approach. $7^{\text {th }}$ edition. McGraw hill; 463.

2. Johnston SL, Holgate ST, editors. Asthma: critical debates. London: Blackwell science; 2003.

3. Rabe KF, Adachi M, Lai CK. Worldwide severity and control of asthma in children and adults: the global asthma insights and reality surveys. J Allergy ClinImmunol. 2004; 114(1): 40-7.

4. Herfindal Eric T, Helms RA, Quinn DJ. Text book of Therapeutics. 2nd ed. Lippincot William and Wilkins; 2002. 658-81.

5. World health organization. bronchial asthma, fact sheet $\mathrm{N}^{\circ} 206$. [Internet] Available from: http://www.who.int/mediacentre/factsheets.

6. Donahue JG, Weiss ST, Livingstone JM, et al. Inhaled steroids and the risk of hospitalization for asthma. JAMA. 1997; 277(11): 887-91.

7. Martin Schulz, Frank Verheyen, et al. pharmaceutical care services for asthma patients a controlled intervention study. Journal of clinical pharmacology. The American college of clinical pharmacology 2001; 41(1): 668-76.

8. Book of adherence to long term therapies- evidence for action- WHO; 2003. 20.

9. Morisky DE, Ang A, Krousel-Wood M, Ward HJ. Predictive validity of a medication adherence measure $\mathrm{m}$ an outpatient setting. J Clins Hypertens. 2008; 10(5): 348-54.

10. Patel Pinal D, patel RK, patel N J, et al. Analysis of prescription pattern and drug utilization in asthma therapy. IRJP. 2012; 108(1): 257.

11. Stock S, Redaelli M, Luengen M, Wendland G, Civello D. Lauterbach Asthma: prevalence and cost of illness. Eur Respir J. 2005; 25: 47-53

12. Wendy Ungar J, Peter Coyte C, et al. Prospective Study of the PatientLevel Cost of Asthma Care in Children. Pediatric Pulmonology 2001; 32(2): 101-8.

13. Chamanpreet S, Gandhi, et al. Assessment of Quality of Life in Children with Asthma and Epilepsy Pediatrics. an open access journal ISSN: 21610665 .

14. Mike Thomas, Tarita Murray-Thomas, Tao Fan. Prescribing patterns of 
asthma controller therapy for children in UK primary care: a cross-sectional BMC Pulmonary Medicine 2010; $10(1)$ : 29. http://www.biomedcentral. com/1471-2466/10/29

15. Gallefoss F, Bakke PS, Rsgaard P. Quality of life assessment after patient education in a randomized controlled study on asthma and chronic obstructive pulmonary disease. Am. J. Respir. Crit. Care Med. 1999; 159(3): 812.

16. Jones PW, Quirk FH, BaveystockCM, Littlejohns P. A self-complete measure of health status for chronic airflow limitation. Am. Rev. Respir. Dis. 1992; 145(6): $1321-7$.

17. Arellano FM, Arana A, Wentworth CE, Vidaurre CF, Chipps BE. Prescription patterns for asthma medications in children and adolescents with health care insurance in the United States. Pediatr Allergy Immunol. 2011; 22(5): 469-76. 